\title{
(2) OPEN ACCESS \\ A huge haemorrhagic suprarenal pseudocyst: an unusual presentation of a rare condition
}

\author{
Adekunle A Olowu (10 1,2 Adel Abbas Alzehairy ${ }^{1}$
}

\begin{abstract}
'Department of Family Medicine, Al Thumama Health Centre, Primary Health Care Corporation, Doha, Qatar ${ }^{2}$ Department of Family Medicine, Weill Cornell Medicine, Doha, Qatar
\end{abstract}

Correspondence to Dr Adekunle A Olowu: kunletinu@hotmail.com

Accepted 10 January 2021
Check for updates

(C) BMJ Publishing Group Limited 2021. Re-use permitted under CC BY-NC. No commercial re-use. See rights and permissions. Published by BMJ.

To cite: Olowu AA Alzehairy AA. BMJ Case Rep 2021;14:e235158. doi:10.1136/bcr-2020235158

\section{SUMMARY}

Haemorrhagic suprarenal pseudocysts are very rare and are often incidental findings at surgery or autopsy, though they can sometimes present with predominantly gastrointestinal or endocrine symptoms, including intraperitoneal bleeding or sepsis. Our case report is of a 48-year-old man who presented at our primary healthcare centre with 2-month history of predominantly respiratory symptoms of cough and shortness of breath. CT scan revealed a suprarenal cyst measuring $14.2 \times 13.5 \times 13.1 \mathrm{~cm}$ for which he was operated and made a full recovery. A detailed literature review reveals that there has never been a case of a haemorrhagic suprarenal pseudocyst presenting with predominantly respiratory symptoms, which is why we decided to document this case report.

\section{BACKGROUND}

Adrenal cystic lesions are very uncommon and are largely pseudocysts. They are rare entities that occur in the fifth and the sixth decades of life. They are difficult to diagnose and are usually discovered accidentally, while occasionally presenting with abdominal or back pain sometimes associated with intraperitoneal bleeding, infection or shock. There are often non-specific clinical and radiological findings. ${ }^{1}$ The majority of adrenal pseudocysts are benign cystic masses originating within the adrenal cortex or medulla that are enclosed by a fibrous wall. It appears that their pathogenesis may lie in repeated episodes of trauma, infection or bleeding. There are four categories of adrenal gland cysts: epithelial, endothelial, parasitic and pseudocysts. ${ }^{2}$ A review of 8 cases in a study in the USA revealed lesion sizes ranging from $1.8 \mathrm{~cm}$ to $10 \mathrm{~cm}$, though the size of the lesion does not correlate with symptoms, but in our case report the lesion was larger. ${ }^{3}$

Intracystic haemorrhage is one of the possible complications of adrenal pseudocysts, which our patient had.

\section{CASE PRESENTATION}

A 48-year-old man who came to our health centre presented with dry cough for almost 2 months with occasional shortness of breath on walking. He had lost around $10 \mathrm{~kg}$ in the last couple of months in addition to symptoms of tiredness and lack of energy. $\mathrm{He}$ also presented with occasional left flank and lower back pain for the last few weeks, as well as 2-week history of fever 6 weeks before presentation. He had no night sweats, haemoptysis or other sinister symptoms. He denied recent travel or sick contacts. He had smoked for long but claimed that he stopped smoking
2 months previously. He had no significant medical history and was not on any regular medications.

On examination, he had mild pallor, looked toxic and was coughing continuously during the consultation. His vital signs were normal.

Cardiovascular system examination revealed normal heart sounds with no added sounds. Respiratory system examination revealed decreased air entry in the left lower lung lobe.

Abdominal examination revealed some tenderness at the left hypochondriac region with no palpable masses.

\section{INVESTIGATIONS}

His complete blood count showed mild hypochromic microcytic anaemia, while his C-Reactive Protein (CRP) was raised at 139, ferritin was also high at 149 and adrenocorticotropic hormone (ACTH) was mildly elevated at 67.9.

Cortisol and aldosterone were normal. His electrolytes, liver and kidney functions were normal. Quantiferon test to rule out tuberculosis was negative. Gastrointestinal endoscopy was not done, but stool occult blood test was negative.

$\mathrm{X}$-rays of the chest, anterior and lateral (figures 1 and 2), revealed an elevated left diaphragmatic dome in the left lower lung zone with bowel loops visible in both anterior and lateral views.

CT scan of the abdomen (figure 3) showed a large well-defined cystic lesion measuring $14.2 \times 13.5 \times 13.1 \mathrm{~cm}$ with a thin wall and areas of rim calcification at the left suprarenal region likely suggestive of suprarenal cyst with proteinaceous/ haemorrhagic contents with eventration of the left diaphragmatic dome. The suprarenal gland was not visualised separately on the left side, while the left lower lung lobe showed evidence of atelectasis of the lower segment. No focal lung lesion was identified. There were no hilar, mediastinal, axillary or supraclavicular lymphadenopathy, and no pleural or pericardial effusion was noted.

\section{DIFFERENTIAL DIAGNOSIS}

Differential diagnosis of suprarenal pseudocysts include benign and malignant lesions which could be adrenal or suprarenal masses like adenocarcinomas or phaeochromocytomas. ${ }^{4}$ Several other rare lesions identified in case reviews include congenital adrenal teratomas as possible differential diagnosis, ${ }^{5}$ as well as a mucinous cystic neoplasm ${ }^{6}$ and prenatally diagnosed adrenal cysts. 


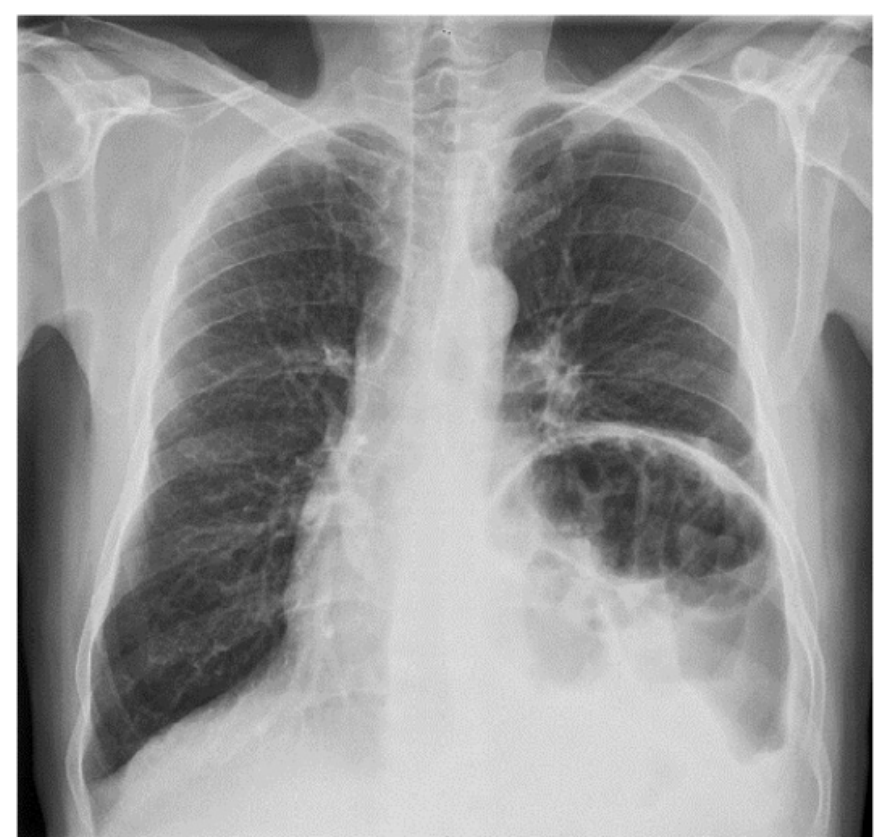

Figure 1 X-ray of the chest (AP view) showing elevated left diaphragmatic dome in the left lower lung zone with visible bowel loops. AP, Anterior-Posterior.

\section{TREATMENT}

The patient was referred urgently to the hospital's accident and emergency department where he had investigations and further management (surgery).

Laparotomy with excision of the cyst with plication of the left dome of the diaphragm under general anaesthesia was performed. Via the same surgical incision for left adrenal mass excision, the floppy diaphragm was taken down with the help of bibcock's 3 lines of $U$ stitches taken with 0 proline starting with the anterior to the posterior. All the three loops were tightened to plicate the

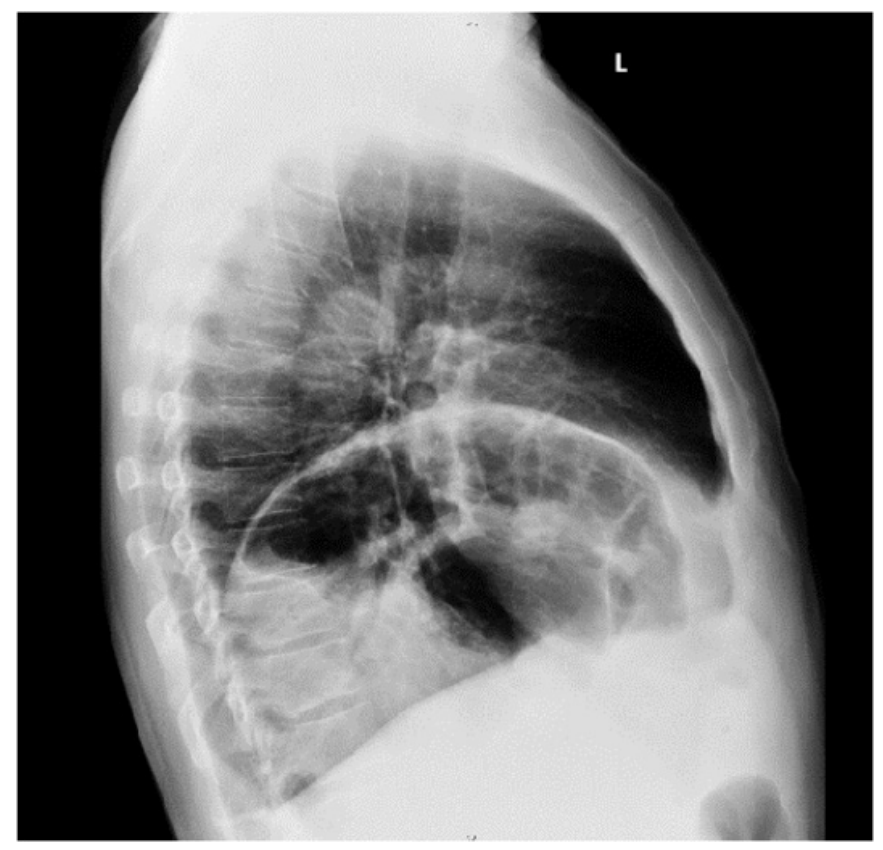

Figure 2 X-ray of the chest (lateral view) showing elevated left diaphragmatic dome in the left lower lung zone with visible bowel loops.

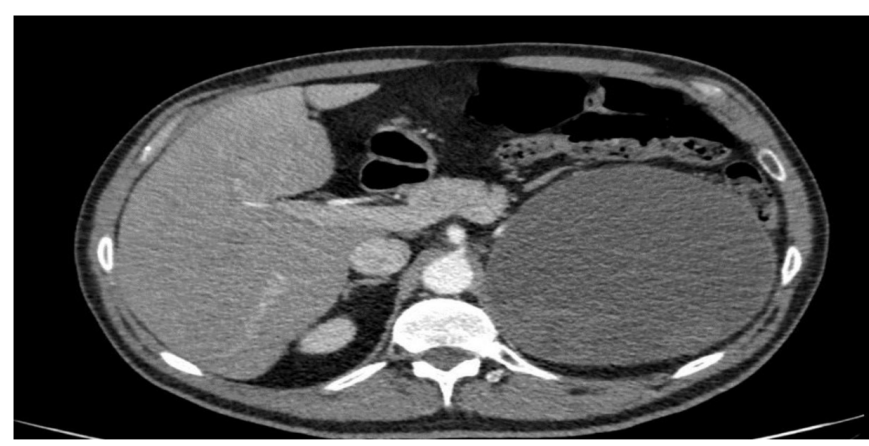

Figure 3 CT scan of the abdomen showing a large well-defined cystic lesion measuring $14.2 \times 13.5 \times 13.1 \mathrm{~cm}$ with a thin wall and areas of rim calcification at the left suprarenal region likely suggestive of suprarenal cyst with proteinaceous haemorrhagic contents with eventration of the left diaphragmatic dome. The suprarenal gland was not visualised separately on the left side, while the left lower lung lobe showed evidence of atelectasis of the lower segment. No other focal lung lesion was identified. There were no hilar, mediastinal, axillary or supraclavicular lymphadenopathy, and no pleural or pericardial effusion was noted.

left dome of the diaphragm. The remaining pop ups were taken individually. At the end, the diaphragm was nicely positioned in its down position. Lower lobes were inflated with positive pressure ventilation by the anaesthetist. Haemostasis was ensured.

\section{OUTCOME AND FOLLOW-UP}

Postoperatively, abdominal and pelvic CT scan showed only an area of hypodensity along the inferior pole of the spleen suggesting a splenic laceration in keeping with surgery with a small subscapular fluid collection stranding. Liver, pancreas and other pelvic organs were normal with no inguinal lymphadenopathy.

Histopathology revealed a huge haemorrhagic suprarenal pseudocyst but unfortunately the photographs of the pathological specimens were not accessible.

The patient made a full recovery postoperatively and all his respiratory symptoms dramatically resolved.

\section{DISCUSSION}

A literature review of several publications on pseudocysts revealed only a few cases documented over several years, often detected at pathological examinations. One of these was a case of a giant adrenal pseudocyst, which was surgically removed. ${ }^{1} \mathrm{~A}$ 20-year review of cystic adrenal lesions at an academic medical centre revealed only 12 pseudocysts out of 31 cysts, out of a total of 4500 adrenal gland specimens reviewed. ${ }^{7}$ They are believed to be associated with tumours and will require surgical excision

\section{Learning points}

- Besides the huge size of the cyst, the uniqueness of this case report is that it is extremely rare to find a haemorrhagic suprarenal pseudocyst presenting with predominantly respiratory symptoms at first presentation.

- Patients can sometimes present with symptoms of rare conditions.

- Irrespective of patient's initial presentation, if there is no remission of symptoms, further investigations are necessary to determine underlying pathology in patients with atypical symptomatology. 
when detected. There was a case report of a haemorrhagic suprarenal pseudocyst presenting as a varicocele. ${ }^{8}$ Another case report documented an adrenal pseudocyst in pregnancy which had to be excised at laparotomy while the pregnancy was carried to term delivery. ${ }^{9} 10$ Treatment is done by surgical excision, which can be done laparoscopically depending on the size of the lesion. ${ }^{2}$ There was no case report of a haemorrhagic suprarenal cysts presenting with predominantly respiratory symptoms of cough and shortness of breath in the literature.

Acknowledgements We are grateful to our patient who agreed and gave consent for this case report, and also to our organisation, the primary healthcare corporation who granted us the approval and permission to submit this case report for publication.

Contributors AAA saw the patient, wrote the clinical case summary as well as obtaining and writing up the patient consent. AAO wrote up the Introduction, Discussion, Literature Review and References and corrected the manuscript before final submission. We both reviewed the final draft before submission.

Funding This study was funded Primary Health Care Corporation Qatar (PHCCl DCR/2020/04/037).

Competing interests None declared.

Patient consent for publication Obtained.

Provenance and peer review Not commissioned; externally peer reviewed.

Open access This is an open access article distributed in accordance with the Creative Commons Attribution Non Commercial (CC BY-NC 4.0) license, which permits others to distribute, remix, adapt, build upon this work non-commercially, and license their derivative works on different terms, provided the original work is properly cited and the use is non-commercial. See: http://creativecommons.org/ licenses/by-nc/4.0/.

\section{ORCID ID}

Adekunle A Olowu http://orcid.org/0000-0002-6231-318X

\section{REFERENCES}

1 Paramythiotis D, Bangeas P, Karakatsanis A. Surgical management of a giant adrenal pseudocyst: a case report and review of the literature in the last decade. Case Reports in Surgery 2018;2018.

2 Ujam AB, Peters CJ, Tadrous PJ, et al. Adrenal pseudocyst: Diagnosis and laparoscopic management - A case report. Int J Surg Case Rep 2011:2:306-8.

3 Medeiros LJ, Lewandrowski KB, Vickery AL. Adrenal pseudocyst: a clinical and pathologic study of eight cases. Hum Pathol 1989;20:660-5 www.pubmed.ncbi.nlm. nih.gov

4 Siekavizza JL, Bernardino ME, Samaan NA. Suprarenal mass and its differential diagnosis. Urology 1981;18:625-32.

5 Yasui Y, Kohno M, Shironomae T, et al. Retroperitoneoscopic resection of a congenital adrenal teratoma in an infant. J Pediatr Surg Case Rep 2013;1:391-4.

6 Kim B-S, Joo S-H, Choi S-I, et al. Laparoscopic resection of an adrenal pseudocyst mimicking a retroperitoneal mucinous cystic neoplasm. World J Gastroenterol 2009;15:2923

7 Sebastiano C, Zhao X, Deng F-M, et al. Cystic lesions of the adrenal gland: our experience over the last 20 years. Hum Pathol 2013;44:1797-803.

8 Geleit R, Bhardwaj R, Fish D. Case report: a unique presentation of a complex haemorrhagic adrenal pseudo cyst 2016

9 Erikci V. A prenatally detected adrenal cyst treated by adrenal-sparing surgery: case report and review of the literature. Annals of Paediatric Surgery 2011;7:1687-4137.

10 Trauffer PM, Malee MP. Adrenal pseudocyst in pregnancy. A case report. J Reprod Med 1996;41:195-7.

Copyright 2021 BMJ Publishing Group. All rights reserved. For permission to reuse any of this content visit

https://www.bmj.com/company/products-services/rights-and-licensing/permissions/

BMJ Case Report Fellows may re-use this article for personal use and teaching without any further permission.

Become a Fellow of BMJ Case Reports today and you can:

- Submit as many cases as you like

- Enjoy fast sympathetic peer review and rapid publication of accepted articles

- Access all the published articles

Re-use any of the published material for personal use and teaching without further permission

Customer Service

If you have any further queries about your subscription, please contact our customer services team on +44 (0) 2071111105 or via email at support@bmj.com.

Visit casereports.bmj.com for more articles like this and to become a Fellow 